\title{
PMSGs Solutions for Gearless Wind Conversion Systems with Battery Storage
}

\author{
T. Tudorache ${ }^{1}$, L. Melcescu ${ }^{1}$, M. Popescu ${ }^{2}$ \\ ${ }^{1}$ University POLITEHNICA of Bucharest, Electrical Engineering Faculty, Electrical \\ Machines Dept., 313 Splaiul Independentei, 060042, Sect. 6, Bucharest (Romania), \\ Phone/Fax number: +0040 21 4029171, e-mail: tudorach@amotion.pub.ro, leonard@amotion.pub.ro \\ ${ }^{2}$ National Institute for R\&D in Electrical Engineering (ICPE-CA), 313 Splaiul Unirii, 030138, Sect. 3, \\ Bucharest (Romania), Phone number: +0040 21 3467231, e-mail: pd_mihail@yahoo.com
}

\begin{abstract}
This paper presents a comparative analysis between a three-phase and a six-phase Permanent Magnet Synchronous Generators (PMSGs) used for small power wind turbines with battery storage. Both studied PMSGs are equipped with diode rectifiers connected across the stator windings terminals. The numerical results are obtained using a 2D Finite Element (FE) analysis of field-circuit coupling type and they emphasize the pros and cons of using three-phase or six-phase PMSGs. The performance analysis includes the evaluation of torque ripples, machine efficiency, voltage and current waveforms and their harmonic distortions, etc. A part of the numerical results are validated by experimental measurements.
\end{abstract}

\section{Key words}

Permanent magnet synchronous generators, three-phase and six-phase machines, finite element analysis.

\section{Introduction}

Various types of electrical generators are used for wind turbines such as: doubly fed induction generators, squirrel cage induction generators, electromagnetic excitation synchronous generators or permanent magnet synchronous generators [1]-[2].

Among the best candidate solutions for wind turbines the Permanent Magnet Synchronous Generator (PMSG) presents the highest efficiency that may easily reach $85 \%$, even for machine configurations with large number of poles (e.g. electric machines for gearless systems) and small power [1], [3].

Another important advantage of PMSGs refers to the high energy density per volume unit, an important issue in wind turbines technology where the overall weight of the nacelle with all the equipment inside should be as low as possible. PMSG offers also a high power factor and a superior reliability due to the lack of sliding contacts. Highly reliable equipment is typically preferred for wind turbines because the maintenance and interventions in remote areas are very costly (especially in case of off-shore wind turbines).

If the high power wind systems connected to the grid are widely analyzed, similar systems with battery storage are less studied. The wind turbines with energy storage in batteries are generally used as common power supply solutions for off grid low power applications such as: isolated households, consumers unconnected to the grid, remote communication systems, pumping and irrigation systems etc. [2]. A pioneering research project recently implemented in US tries to extend this energy production/storage concept to other levels. This project proposes a special system for electric energy storage in huge capacity batteries (several GWhs) aimed to be used as load leveling solution for power grids [4]. Gradually, with the drop of the batteries price, such systems could represent interesting and reliable solutions able to store the wind energy in excess and to deliver it to the grid when necessary.

A PMSG based wind conversion system with battery storage requires usually the presence of a controlled or uncontrolled diode bridge rectifier interposed between the generator and the battery [1]. The uncontrolled rectifiers are cheaper but they may provoke current harmonics in the PMSG phase windings [5]. The controlled rectifiers are more expensive but, if well designed, they can improve the phase currents waveform of PMSG reducing the harmonics amplitudes.

Though the PMSGs for wind turbines are typically equipped with a three-phase winding, several multi-phase variants were analyzed in the last years [6]-[7]. The advantages of a multi-phase PMSG compared to the classical three-phase variant can be summarized as follows: the high currents (in case of large power machines) may be divided among several phases, low harmonic distortion and lower acoustic noise at the same power level, improved efficiency, better stability, higher fault tolerance ability, etc. [8]. 
In studies like [6]-[7] six-phase PMSGs are studied in comparison with three-phase ones using simplified circuit models. The numerical results prove the advantages of sixphase PMSG. Unlike these simplified circuit models, those used in this paper are more complex, based on field-circuit type couplings, being solved by Finite Element (FE) method.

Though a FE analysis of PMSGs supposes a larger CPU time, the computation accuracy is higher, allowing us to detect tooth harmonics, to take into account magnetic nonlinearities and to evaluate the eddy current losses in the rotor (in permanent magnets and rotor core) and the machine efficiency.

\section{FE Model of the Studied Machines}

The main reference data of the studied PMSG are the following: rated power $400 \mathrm{~W}, 10$ poles, 36 slots, stator bore diameter $90 \mathrm{~mm}$, stator outer diameter $128 \mathrm{~mm}$, axial length $15 \mathrm{~mm}$, no skewing, Fig. 1.

The permanent magnets are made of $\mathrm{NdFeB}\left(\mu_{\mathrm{r}}=1.08756\right.$, $\left.\mathrm{B}_{\mathrm{r}}=1.23 \mathrm{~T}\right)$, the stator core is made of electric steel laminations of M600-50A type and the rotor core is made of common solid steel.

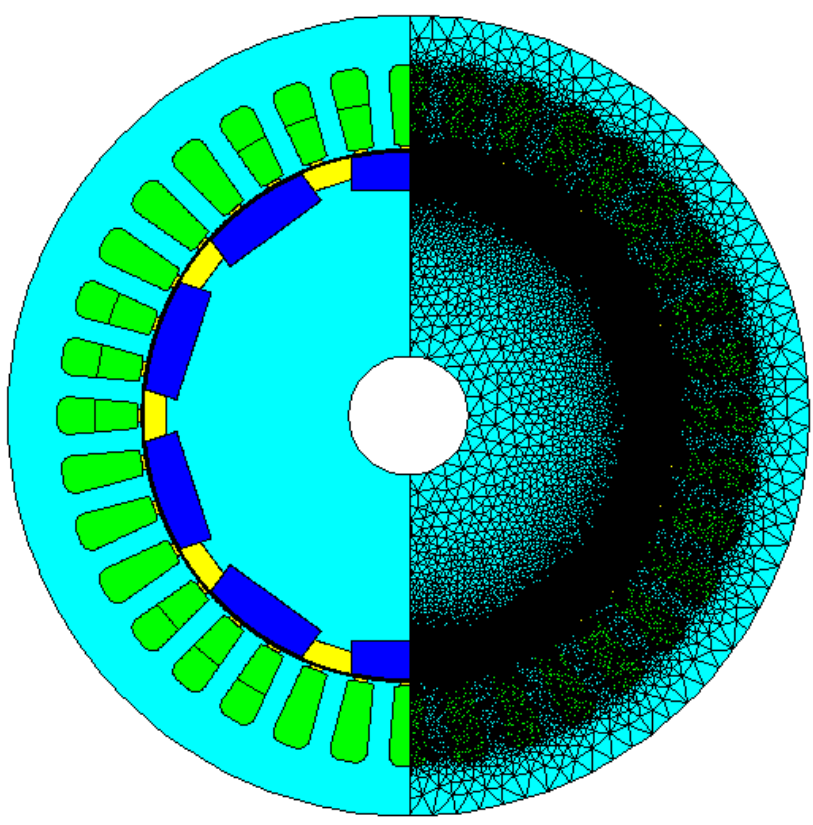

Fig. 1. Cross-section through the studied PMSG; 2D FE computation domain and mesh.
The eddy current losses in the permanent magnets and in the rotor magnetic core that are due to the magnetic field harmonics in the machine airgap are taken into account by considering these regions as electrically conductive. The electrical resistivity considered for permanent magnets is $1.510^{-6} \Omega \mathrm{m}$ and for the rotor steel $0.2510^{-6} \Omega \mathrm{m}$. The hysteresis losses in the rotor regions are neglected.

The windings diagram of the six-phase PMSG is shown in Fig. 2 and it has 78 turns/phase and 13 turns/coil. It consists of two star connected three-phase windings electrically shifted with $30^{\circ}$. The stator windings diagram of the three-phase PMSG is detailed in [9].

The 2D FE computation domain represented by a crosssection through the PMSG and the associated finite element mesh are shown in Fig. 1. The mesh building process was carefully treated since the PMSG models take into account the eddy current losses in permanent magnets and rotor magnetic core. A precise computation of these losses requires a more refined mesh of these regions toward the machine airgap, Fig. 1. A limitation in the computation of these losses comes from the very nature of the 2D FE model of the machine that is not able to take into account the $3 \mathrm{D}$ effects.

The transient magnetic analysis of the PMSG is based on the following partial differential equation derived from Maxwell's equations [10]:

$$
\operatorname{curl}\left[(1 / \mu) \cdot \operatorname{curl} \mathbf{A}-\mathbf{H}_{\mathbf{c}}\right]-\mathbf{J}_{\mathbf{s}}+\sigma \cdot \partial \mathbf{A} / \partial \mathrm{t}=0
$$

where $\mathbf{A}$ represents the magnetic vector potential, $\mu$ is the magnetic permeability that is non-liner in the magnetic cores regions, $\mathbf{H}_{\mathbf{c}}$ is the coercive magnetic field of permanent magnets, $\mathbf{J}_{\mathbf{s}}$ is the current density (apriori unknown) flowing through the stator windings, $\sigma$ is the electric conductivity of solid conductors (i.e. rotor core and permanent magnets).

The boundary conditions imposed on the outer border of the stator region and on the inner border of the rotor region (towards the machine shaft) are of tangential magnetic field type $(\mathbf{B} \cdot \mathbf{n}=0)$. Since the current density $\mathbf{J}_{\mathbf{s}}$ in (1) is not apriori known, the field models of the PMSGs should be coupled to the associated circuit models of the studied machines, Fig. 3. Diode bridge rectifiers are connected across the machines terminals for both three and six-phase PMSGs arrangements.

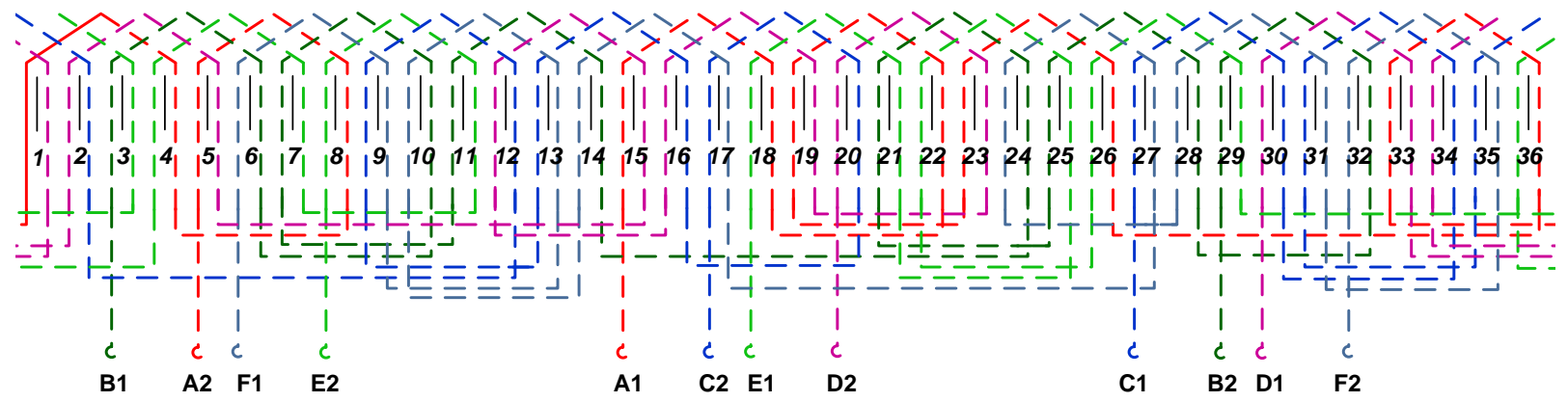

Fig. 2. Winding diagram of six-phase PMSG. 


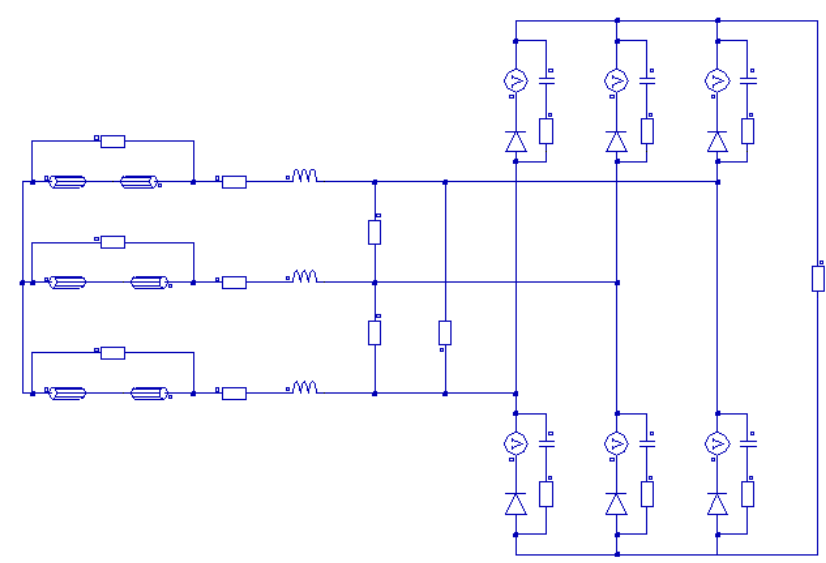

a)

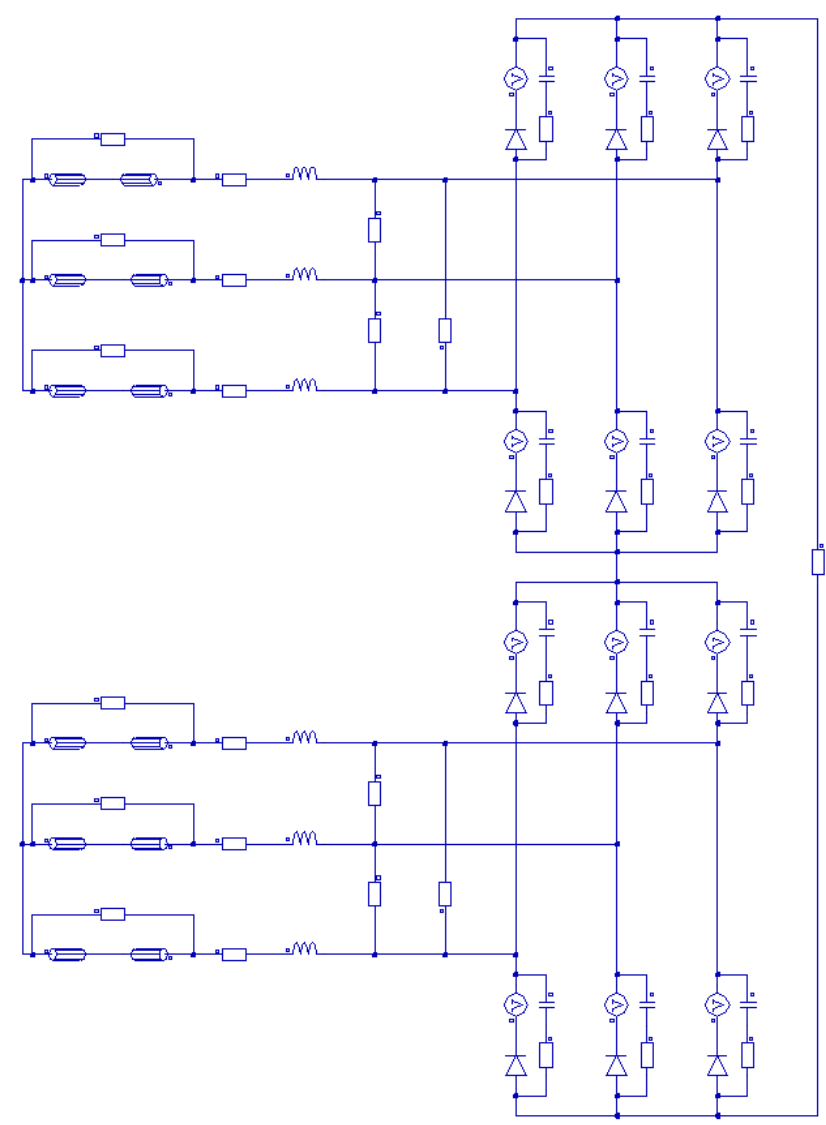

b)

Fig. 3. Circuit models of three-phase (a) and six-phase (b) PMSGs with diode bridge rectifiers.

The circuits above include the positive/negative sides of the stator phase windings (for three and six-phase structures), the phase resistances, the end winding inductances per phase, several voltmeters (with large value resistances), diodes bridge rectifiers and a resistive load. The values of the load resistor can be modified so as to model various load conditions (e.g. no load, rated load, overload, etc.).

The stator iron losses are modeled by properly sized resistances connected in parallel with the stator coils. These losses are computed by an incremental method. First of all the computations are made for approximate value of these resistances. Then the losses over an e.m.f. cycle are computed in post-processing using the method implemented in Flux software package [10] and the initial values of iron losses resistances are corrected.

The diode model includes an ideal diode series connected to a forward voltage source. An RC snubber circuit is connected in parallel to each diode of the rectifier to attenuate eventual voltage transients in the circuit, ensuring thus a better operation of the converter.

\section{Numerical Results}

By solving the transient magnetic field problem associated to the PMSG in no-load conditions (without rectifier) we obtained the magnetic field lines and the magnetic flux density chart shown in Fig. 4.

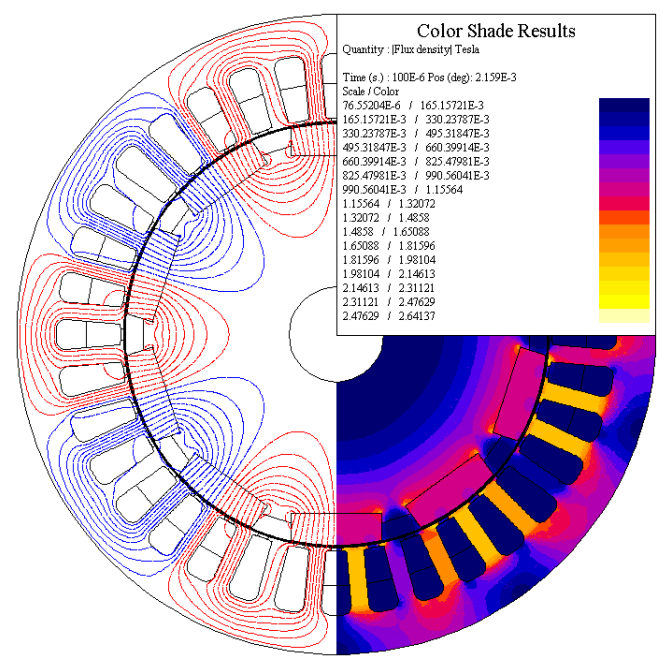

Fig. 4. Magnetic flux density chart and field lines.

The numerical simulations of the studied PMSGs operation under load conditions were carried out for a resistive load of $9.6 \Omega$. This circuit arrangement can model a simplified battery charging process, the load resistor representing the battery resistance series connected to a current limiting resistor.

By a transient magnetic analysis of the studied PMSGs we obtained the time variations of the rectified voltages and currents shown in Figs. 5 and 6. These results emphasize a far smaller current/voltage ripples in case of six-phase PMSG compared to the case of three-phase PMSG (only 5.74\% compared to $13.23 \%$ ).

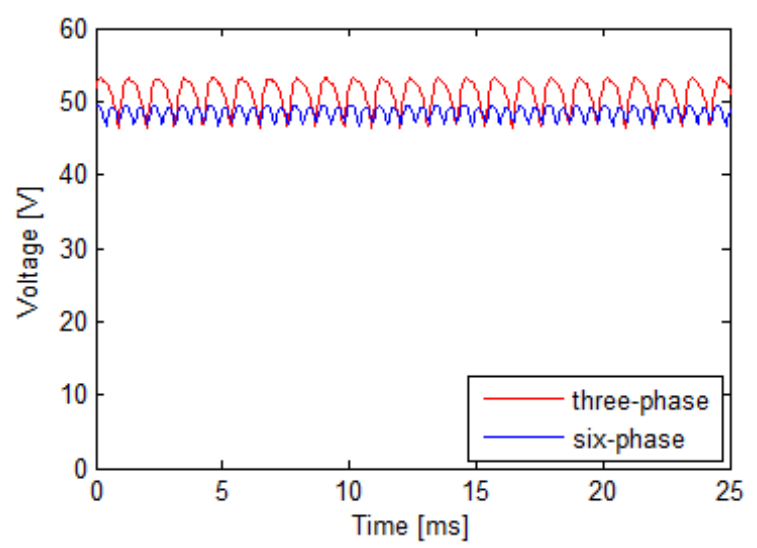

Fig. 5. Rectified voltages of three-phase and six-phase PMSGs. 


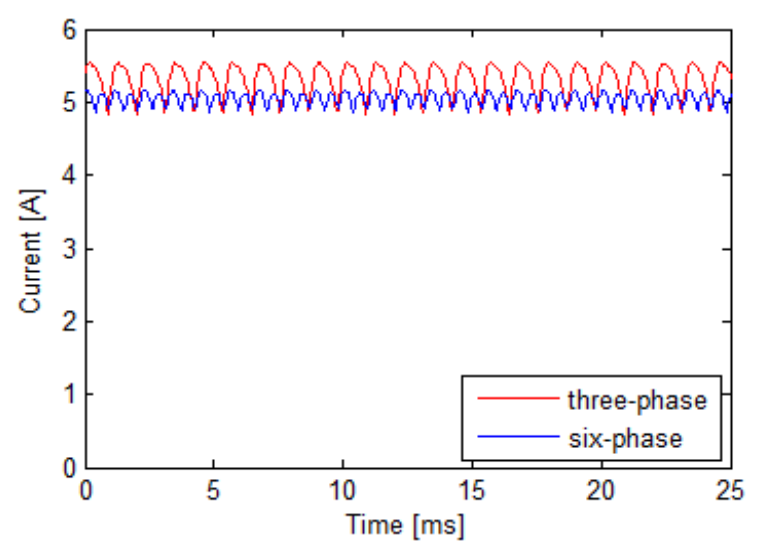

Fig. 6. Rectified currents of three-phase and six-phase PMSGs.

The waveforms of line voltages and phase currents obtained for the same load resistance of $9.6 \Omega$ are shown in Figs. 7 and 8 and their harmonics spectra in Fig. 9. The line voltage in case of six-phase PMSG is about two times smaller than in case of three-phase PMSG because the number of turns per phase is two times smaller as well. The FFT analysis reveals that the six-phase PMSG (compared to the three-phase PMSG) leads to smaller $5^{\text {th }}$ order harmonic amplitude of the line voltages $(11.9 \%$ compared to $17.1 \%)$ and of the phase currents $(14.7 \%$ compared to $16.4 \%$ ). On the contrary the amplitude of the $7^{\text {th }}$ order harmonic of the phase currents and line voltages slightly increases (from $6.3 \%$ to $8.14 \%$ for phase currents and from $7.76 \%$ to $8.9 \%$ for line voltages). Other visible harmonics of the voltages and currents are the $11^{\text {th }}, 13^{\text {th }}$, $17^{\text {th }}$ and the $19^{\text {th }}$. The numerical analysis was limited in this study to the $20^{\text {th }}$ order harmonic.

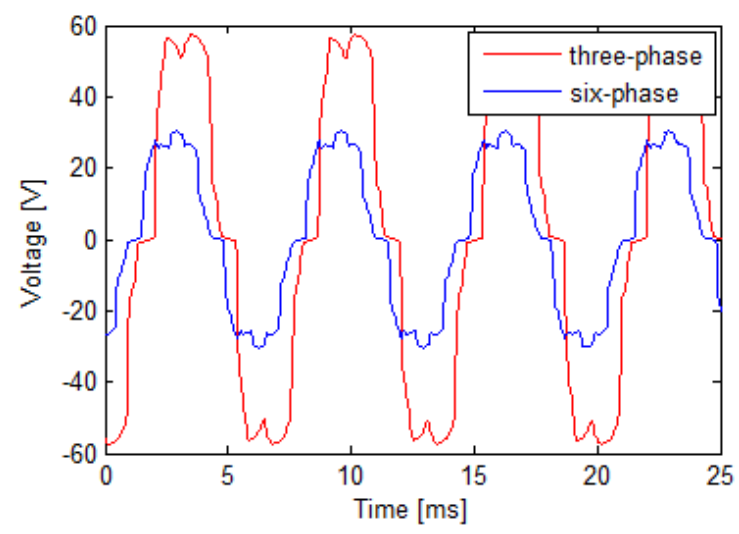

Fig. 7. Line voltages of three-phase and six-phase PMSGs.

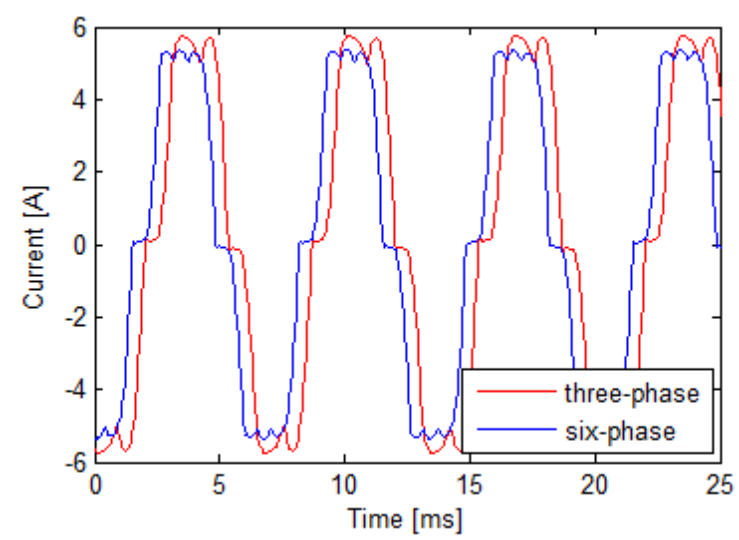

Fig. 8. Phase currents of three-phase and six-phase PMSGs.

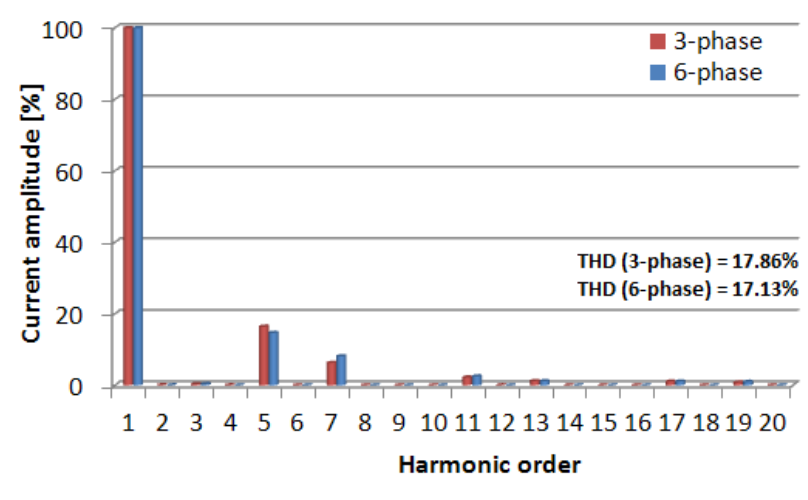

a)

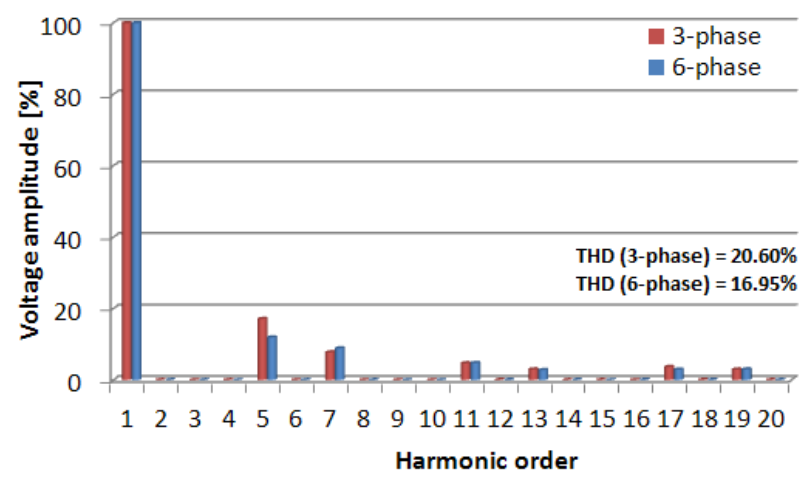

b)

Fig. 9. Spectrum analysis of phase currents and line voltages of threephase and six-phase PMSGs; a) phase currents; b) line voltages.

Slightly lower THD values can be noticed in Fig. 9 in case of six-phase PMSG compared to the three-phase PMSG, for both the phase currents $(17.13 \%$ compared to $17.86 \%)$ and line voltages $(16.95 \%$ compared to $20.60 \%)$.

The time variations of the electromagnetic torques for the two studied PMSGs (for the same resistive load of 9.6 $\Omega$ ) are presented in Fig. 10. An important decrease of the torque ripples can be noticed in case of six-phase machine compared to the three-phase machine $(3.57 \%$ compared to $13.23 \%$ ). Smaller torque ripples represents an advantage in the exploitation of the PMSG since they determine smaller mechanical vibrations and a longer bearings lifetime.

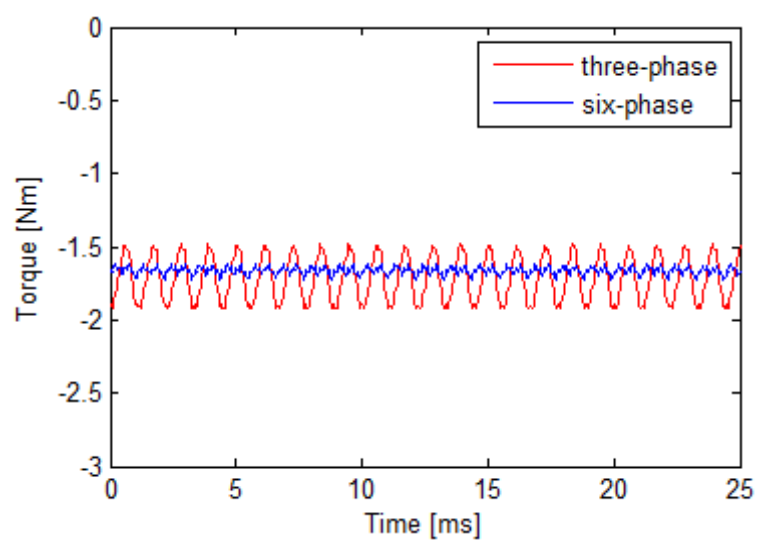

Fig. 10. Time variation of electromagnetic torque of three-phase and six-phase PMSGs. 
The evaluation of PMSG efficiency is computed using the formula:

$$
\eta=P_{2} / P_{1}
$$

where $\mathrm{P}_{1}$ is the mechanical power received by the generator at the rotor shaft from the prime mover, and $\mathrm{P}_{2}$ is the active power delivered by the machine.

The input power $P_{1}$ is computed by multiplying the machine torque with the rotor angular speed. The active power $\mathrm{P}_{2}$ can be computed based on the following formula:

$$
\mathrm{P}_{2}=\mathrm{P}_{1}-\mathrm{P}_{\mathrm{m}}-\mathrm{P}_{\mathrm{ed}}-\mathrm{P}_{\mathrm{Js}}-\mathrm{P}_{\mathrm{Fe}}
$$

where $\mathrm{P}_{\mathrm{m}}$ represents the mechanical losses, $\mathrm{P}_{\mathrm{Js}}$ the Joule losses in the stator windings, $\mathrm{P}_{\text {ed }}$ the eddy current losses in the permanent magnets and rotor core, $\mathrm{P}_{\mathrm{Fe}}$ the iron losses in the stator core. The mechanical losses $\mathrm{P}_{\mathrm{m}}$ of each of the two PMSGs are estimated at about $10 \mathrm{~W}$. The hysteresis losses in the rotor part are neglected.

The power losses and the efficiency for both studied PMSGs are presented in Table I for the same resistive load of $9.6 \Omega$ connected across the rectifier terminals. We can notice that the efficiencies of the two machines are comparable, slightly higher in case of the six-phase PMSG.

Table I. Types of losses and efficiency of studied PMSGs

\begin{tabular}{|l|l|l|l|l|l|l|}
\hline \multirow{2}{*}{$\begin{array}{l}\text { PMSG } \\
\text { type }\end{array}$} & $\mathrm{P}_{1}$ & $\mathrm{P}_{\text {ed }}$ & $\mathrm{P}_{\mathrm{Js}}$ & $\mathrm{P}_{\mathrm{Fe}}$ & $\mathrm{P}_{2}$ & $\eta$ \\
\cline { 2 - 7 } $3 \mathrm{Wh}$ & 322.53 & 1.48 & $1 \mathrm{~W}]$ & {$[\mathrm{W}]$} & {$[\mathrm{W}]$} & {$[\%]$} \\
\hline $6 \mathrm{Ph}$ & 313.86 & 1.28 & 14.15 & 12.97 & 287.45 & 87.57 \\
\hline
\end{tabular}

The distribution of eddy currents in particular regions of the permanent magnets and of the rotor core are shown in Fig. 11. These simulation results are useful to emphasize the rotor regions with high induced power densities that may generate local hot spots. Even though the losses in the permanent magnets and rotor core are not so important in our case, they can be much larger in case of PMSG with higher harmonics magnetic fields in the airgap region (e.g. for fractional-slot windings). The overheating produced by such hot spots in case of PMSG with permanent magnets directly glued on the rotor surface may entail even their ungluing, especially if the machine is characterized by high torques.

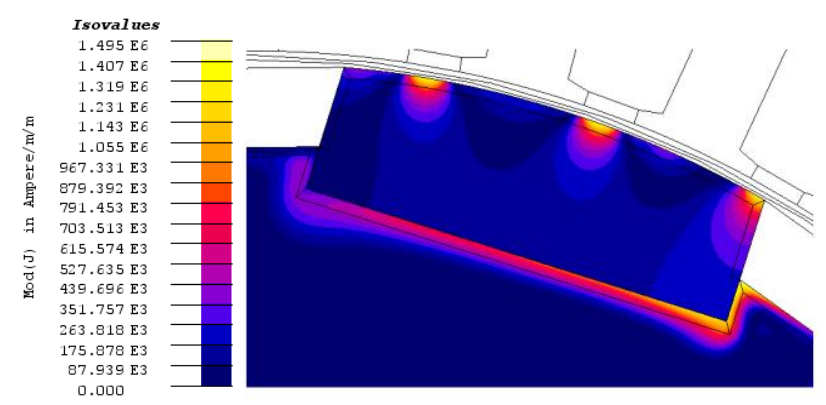

Fig. 11. Eddy current density distribution in particular regions of permanent magnets and rotor core in case of three-phase PMSG.

\section{Experimental Results}

The experimental studies are limited only to the threephase PMSG equipped with a diode rectifier and a resistive load. The experimental setup includes an inverter fed induction motor, a three-phase PMSG, a diode rectifier, load rheostats, etc. The experimental measurements are carried out using a Tecktronix digital oscilloscope with 4 channels and several voltage and current sensors, Fig. 12. The numerical and experimental results are presented comparatively in Fig. 13.

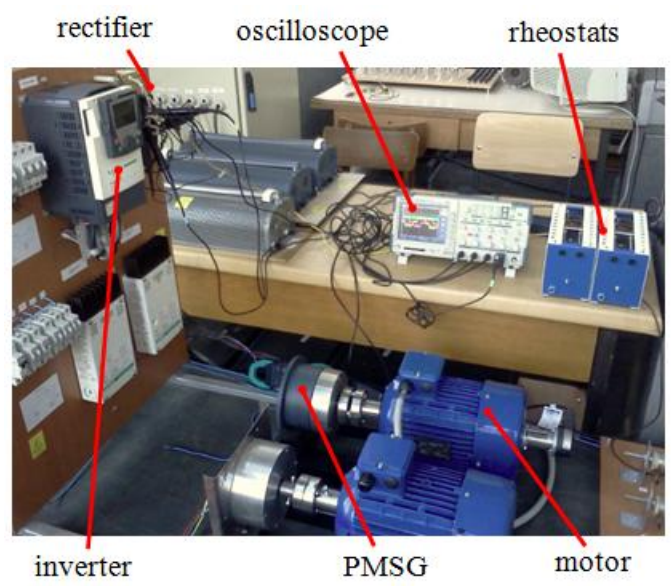

Fig. 12. Experimental setup used to study the three-phase PMSG equipped with diode rectifier.

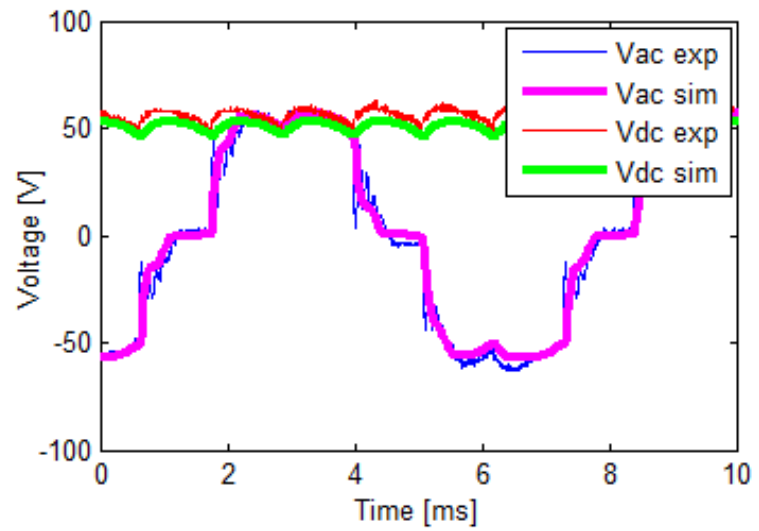

a)

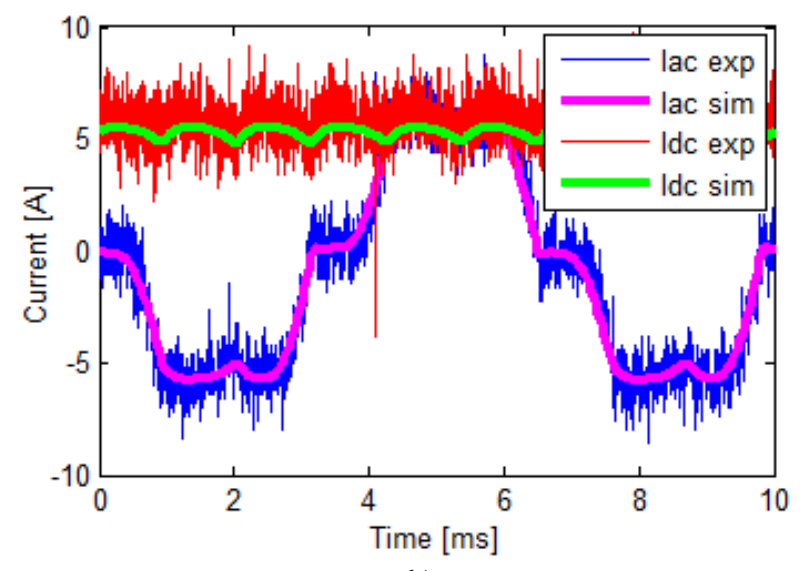

b)

Fig. 13. Validation of numerical results for three-phase PMSG (exp - experimental results; sim - simulation results); a) Vac line voltage; Vdc - rectified voltage; b) Iac phase current; Idc rectified current. 
A good agreement can be noticed between the numerical and experimental results. Typical higher noise level can be remarked in case of experimental results, especially in case of recorded currents, Fig. 13 b).

\section{Conclusion}

This paper presents a detailed comparative analysis of three-phase and six-phase PMSGs. The numerical analysis results emphasize the behavior of both PMSGs structures when operating in load conditions.

The results show that the phase currents and line voltages in case of three-phase PMSG have a slightly larger harmonic content (larger THD values) compared to the six-phase PMSG. The electromagnetic torque ripples are also much larger in case of three-phase PMSG.

The eddy current losses, the copper losses and the iron losses are slightly larger in case of three-phase PMSG compared to the six-phase machine. The efficiencies of the two machines are comparable, slightly larger in case of the six-phase PMSG.

A part of the numerical results were experimentally validated by laboratory measurements. The agreement between the numerical and experimental results is good.

\section{Acknowledgement}

The work has been co-funded by the Sectoral Operational Programme Human Resources Development 2007-2013 of the Romanian Ministry of Labour, Family and Social Protection through the Financial Agreement POSDRU/89/1.5/S/62557.

\section{References}

[1] L. H. Hansen, L. Helle, F. Blaabjerg, E. Ritchie, S. MunkNielsen, H. Bindner, P. Sørensen and B. Bak-Jensen, "Conceptual survey of Generators and Power Electronics for Wind Turbines", Research Report (Risø-R-1205), Risø National Laboratory, Roskilde, Denmark, December 2001.

[2] G. Johnson, "Wind Energy Systems", Electronic edition, US, 2006.

[3] A. Binder, T. Schneider, "Permanent Magnet Synchronous Generators for Regenerative Energy Conversion - A survey", Proc. of European Conference on Power Electronics and Applications, 2005, pp 1-10.

[4] J. Kumagai, "A Battery as Big as the Grid", IEEE Spectrum, pp 1 - 2, January 2012, US.

[5] P. Lampola, "Directly Driven, Low-Speed PermanentMagnet Generators for Wind Power Applications", Acta Polytechnica Scandinavica, Electrical Engineering Series, No.101, Espoo, 2000.

[6] S. Kato, Y. Inui, M. Michihira, A. Tsuyoshi, "A Low-Cost Wind Generator System with a Permanent Magnet Synchronous Generator and Diode Rectifiers", Proc. of ICREPQ 2007, paper 212, pp 1 - 7.

[7] P. H. B. Naves, J. C. Oliveira, A. F. Bonelli, M. V. B. Mendonça, "Modelling and Comparative Performance Analysis of Special Six-phase and Conventional Synchronous Generators for Wind Farm Application", Proc. of ICREPQ 2009, paper 367, pp 1 - 6.

[8] J. Björk-Svensson, J.O. Munoz Pascual, "Torque control of a wind turbine using 6-phase synchronous generator and a dc/dc converter", Thesis, Dept. of Energy and Environment, Chalmers Univ. of Technology Göteborg, Sweden 2007.

[9] T. Tudorache, M. Popescu, "Optimal Design Solutions for Permanent Magnet Synchronous Machines”, AECE Journal, Vol. 11, Issue 4, pp. 77 - 82, 2011.

[10] ***, "Flux 10. User's Guide. Vol. 3. Physical applications: Magnetic, Electric, Thermal”, CEDRAT, 2007. 